\title{
For Grandparents' Sake: the Relationship between Grandparenting Involvement and Psychological Well-Being
}

\author{
Eon-Ha Park ${ }^{1}$
}

Published online: 16 January 2018

C) The Author(s) 2018. This article is an open access publication

\begin{abstract}
The study examined the impact of role type and involvement level on psychological wellbeing among 255 South Korean grandparents. Participants in nonbaseline role types (those who participated in grandparenting) tended to perceive meaning in their lives and to exhibit relatively low levels of stress and depressive mood. With respect to involvement, stress tended to decrease $(\beta=-0.134)$ when this variable increased, but no relationship was found with perceived meaning or depressive mood. In addition, the hypotheses that burden of caring for grandchildren would mediate the impact of role type and involvement level on psychological wellbeing, and that respect from adult children would moderate this mediation, were supported. Four policy and practice implications are identified. First, policy makers should provide resources for seniors so that those who might benefit from actively nurturing their grandchildren can do so more readily. Second, given that significant moderated mediation emerged in terms of care burden and grandparent roles and involvement, practitioners should be aware of the interactions among grandparents, children, and grandchildren when providing counselling and other resources. Third, the study suggests the importance of applying dynamic practice models, particularly in a context like South Korea, where most families encompass more than two generations. Finally, the results have implications regarding the impact of grandparent attitudes and behaviour patterns within changing social dynamics, and practitioners should be prepared to assist clients and their families to address their evolving roles and the impacts they have on the family unit. Limitations and implications for future research are also discussed.
\end{abstract}

Keywords Grandparenting · Role-meaning - Level of involvement · Burden of care · Psychological well-being

Eon-Ha Park

ehp221@naver.com

1 Department of Social Welfare and Early Child Education, Daedong College, Geum-Jeong-Gu, Dong-Bu-Gok-Ro 27, Beon-Gil 88, Busan 46270, South Korea 


\section{Introduction}

While societal changes may increasingly undermine roles traditionally played by grandparents, improvements in healthcare, hygiene, and nutrition have substantially increased average life expectancies. As a result, many grandparents are living longer and remaining healthy and active into old age. Additionally, changes in working conditions associated with urbanization, along with the employment of women outside the home, have forced many families to depend more heavily on grandparents for primary caregiving of their grandchildren while the parents are at work (Cherlin and Furstenberg 1986). In South Korea, where the present study was conducted, a considerable rise in suicides among economically challenged elderly individuals occurred over two decades in the late twentieth and early twenty-first century (Seoul Statistical Office 2005). In this light, studies that inquire into the potential impact of grandparenting roles on health and happiness can contribute to the understanding of whether certain types or levels of grandparenting involvement should be considered as potential risk factors - or, perhaps, as potential factors mitigating against risk-for elderly individuals.

To contribute to the understanding of how caregiving affects grandparents, the study examined the impact of four previously identified grandparenting role types, along with involvement level, on grandparents' psychological well-being. Psychological wellbeing was measured through depressive mood and stress indices, as well as the extent to which participants perceived meaning in their lives. Hypotheses reflected the expectation, based on a review of relevant literature, that childcare burden would act as a mediator on the relationship between grandparenting role type/involvement level and psychological well-being. Moreover, the study also found that respect accorded to grandparents (by the parents) could moderate this mediating effect of childcare burden.

\section{Types and Impact of Grandparenting Involvement}

The present study was designed to potentially capture both positive and negative impacts of a variety of forms and levels of caregiving on grandparents' psychological well-being. Notably, many previous studies assessing the grandparent-grandchild relationship have focused on the adverse consequences of custodial grandparenting. Contributing factors identified in this regard include inadequate living conditions experienced by custodial grandparents, difficulties experienced when caring for grandchildren, and problematic behaviours among grandchildren raised by custodial grandparents (Kwon 2000; Ohk 2005). Negative health effects of stress and depression experienced by grandparents caring for their grandchildren are also discussed by Burton (1992), Goodman and Silverstein (2002), Kelley et al. (2000), Minkler et al. (1997), Rodgers-Farmer (1999), Strawbridge et al. (1997), and Szinovacz et al. (1999).

Indeed, grandparents who participate substantially in caring for their grandchildren often face stressors that can adversely affect their health and well-being. Moreover, in addition to childrearing pressures, grandparents who anticipated a leisurely retirement - or expected to play more companionate roles with their adult children - may resent the demands associated with being expected to raise their grandchildren. In this regard, many grandparents who take on a major childcare role complain of feeling 'off track' (Neugarten 1976), which is to say that they perceive their current caregiver role 
as inconsistent with their late life expectations. Hence, they may feel physically unable to cope with raising young children (Goodman and Silverstein 2002). Similarly, pressures can arise from the fact that grandparents may lack knowledge or experience regarding new technologies with which their grandchildren are (or need to be) familiar. In other words, grandparents may not recognize or understand the skills that their grandchildren will need in order to succeed in the modern workplace (Strom et al. 2008).

Although grandparents face many challenges and incur social and personal costs when raising their grandchildren, such relationships can also entail benefits for the caregiver. Indeed, researchers have long been aware that many grandparents feel psychologically rewarded through helping their adult children and that they appreciate the opportunity to redress their perceived failures with their own children (Neugarten et al. 1968). According to a number of more recent studies, moreover, the rewards of raising grandchildren can include feeling younger, perceived or actual increases in longevity, finding meaning in life, reforming familial and other relationships, and achieving personal satisfaction, intimacy, and love (Chen and Silverstein 2000; Cox 2000; Jendrek 1994).

Gonzalez and Anuncibay (2008) looked at grandparents' role as caregivers in the context of a variety of tasks that grandparents might engage in with their grandchildren. In a survey of 603 grandparents in Burgos, Spain, the researchers found that while many grandparents were engaged in looking after their grandchildren, they also commonly engaged in such leisure activities as reading together, playing, or going to the park. The authors also noted that grandparents often assumed the role of caregiver in response to the parents' needs rather than their own needs as grandparents, and that most grandparents saw their primary role as grandparents as consisting of one or more of the following: a) playing with their grandchildren, b) indulging them, c) providing them with unconditional love.

While nurturing their grandchildren, grandparents sometimes find that their lives become more fulfilling as they find new meaning and purpose in life. In other words, while sharing their wisdom and experience with their grandchildren, they often find meaning in their own existence, and their sense of pride increases as they perceive themselves as people who play essential roles in their grandchildren's growth and development (Kennedy and Keeney 1988; Kim 2006). They perceive grandparenting as an opportunity to experience, though perhaps differently, some of the diverse emotions that they experienced in the past, and they may feel a sense of satisfaction at the opportunity to nurture their grandchildren in ways that they may not have been able to nurture their children (Burton 1992). Thus, grandparents sometimes consider even their grandchildren's mischievous acts or lack of respect as a consolation in life (Lee 2005).

Indeed, studies have shown that most grandparents express that they find new meaning in life when nurturing their grandchildren, but it is also known that many have mixed feelings about their role in acting as a proxy for the grandchildren's parents (Kornhaber and Forsyth 1994). Grandmothers, in particular, experience more negative feeling compared to grandfathers; moreover, although grandparents are typically grateful for the opportunity to nurture their grandchildren and value this role, Minkler et al. (1997) also found that most grandparents not only manifested emotional conflict but also experienced depression and burnout. Nonetheless, these authors found that 
grandparents' nurturing of their grandchildren could enrich the grandparents' lives by giving them new meaning, and that close interaction with their grandchildren could have a positive impact on the grandparents' emotional wellbeing.

\section{Hypotheses}

According to social exchange theory, grandparenting takes place within the context of an intergenerational balance (Marbach 1995). For instance, grandparents provide support and care for their grandchildren (e.g., babysitting and education) in exchange for various forms of assistance (e.g., instrumental and emotional support) from their adult children. However, social exchange theory is based on an economic model of human behaviour, and critics have argued that this theory does not account for social norms or emotions that promote a sense of familial solidarity, or even altruistic behaviour (Park 2012). In the Korean context, moreover, it is important to take account of Confucian moral values, according to which the family is both the core of and the model for social organization (Fan 2006). Thus, each individual bears a responsibility for maintaining familial integrity, and this responsibility does not depend on-and cannot be reduced to - a balance between individual interests.

In framing the study's hypotheses, it was therefore understood that grandparents provided nurturance to their grandchild - actively or otherwise - for the same reasons that a parent nurtures the child, as well as that the adult children (typically) demonstrated deference and respect toward the grandparents. Figure 1 illustrates the relationship among the key variables in the study, i.e., grandparenting role type, involvement level, and psychological well-being, as well as the relationships among these variables, the mediating factor of childcare burden, and the moderating factor of respect accorded to grandparents (by the parents). Thereafter, the hypotheses are stated and explained.

Hypothesis 1. Grandparent role types and involvement level will have a relationship to their psychological wellbeing.

$$
\begin{aligned}
& \mathrm{Y} 1=\mathrm{B}^{0}+\mathrm{B}^{1} \mathrm{X}^{1}+\text { Controls. } \\
& \mathrm{Y} 1=\mathrm{B}^{0}+\mathrm{B}^{2} \mathrm{X}^{2}+\text { Controls. }
\end{aligned}
$$

Hypothesis 2. Grandparent role types and involvement level will have a relationship to their burden of caring for grandchildren.

$$
\begin{aligned}
& \mathrm{Y} 2=\mathrm{B}^{0}+\mathrm{B}^{1} \mathrm{X}^{1}+\text { Controls. } \\
& \mathrm{Y} 2=\mathrm{B}^{0}+\mathrm{B}^{2} \mathrm{X}^{2}+\text { Controls. }
\end{aligned}
$$

Hypothesis 3. The burden of caring for grandchildren will act as a mediator between the role types and level and psychological wellbeing.

$$
\begin{aligned}
& \mathrm{Y} 2=\mathrm{B}^{0}+\mathrm{B}^{1} \mathrm{Y}^{1}+\mathrm{B}^{2} \mathrm{X}^{1}+\text { Controls. } \\
& \mathrm{Y} 2=\mathrm{B}^{0}+\mathrm{B}^{1} \mathrm{Y}^{1}+\mathrm{B}^{3} \mathrm{X}^{2}+\text { Controls }
\end{aligned}
$$

(Here $\mathrm{B}^{2}$ and $\mathrm{B}^{3}$ should be close to zero or at least reduce.) 


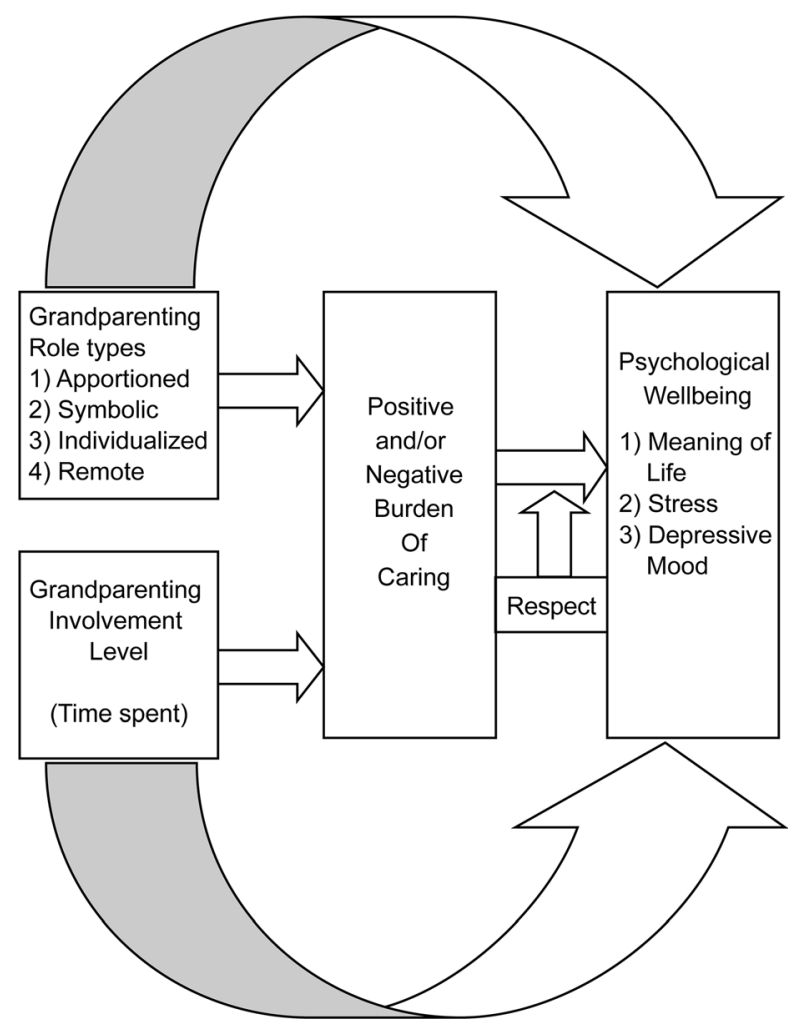

Fig. 1 Impact of role type, involvement level, burden, and respect on grandparents' psychological well-being

Hypothesis 4. The respect accorded to grandparents will act as a moderator between the burden of caring and psychological wellbeing.

$$
\begin{aligned}
& \mathrm{Y} 2=\mathrm{B}^{0}+\mathrm{B}^{1} \mathrm{Y} 1+\mathrm{B}^{2} \mathrm{X} 1+\mathrm{B}^{3} \mathrm{X} 2+\mathrm{B}^{4} \mathrm{Z}+\mathrm{B}^{5}\left(\mathrm{Y} 1^{*} \mathrm{Z}\right)+\text { Controls. } \\
& \mathrm{Y} 2=\mathrm{B}^{0}+\mathrm{B}^{1} \mathrm{Y} 1+\mathrm{B}^{2} \mathrm{X} 2+\mathrm{B}^{4} \mathrm{Z}+\mathrm{B}^{5}\left(\mathrm{Y} 1^{*} \mathrm{Z}\right)+\text { Controls. }
\end{aligned}
$$

$\left(\mathrm{B}^{5} \text { is significant and large. }\right)^{1}$

\section{Methods}

\section{Sample and Recruitment Procedures}

To identify prospective participants, 14 kindergartens were selected randomly from a list posted by the Alliance of Kindergartens in Seoul, South Korea (2010). At the request of the researcher, staff at these kindergartens facilitated contact with the children's grandparents. This study was approved by the ethical review board of the researcher's home institution. Informed consent was obtained from all individual

\footnotetext{
${ }^{1} \mathrm{Y} 1$ = Burden of caring; $\mathrm{Y} 2$ = Psychological wellbeing; $\mathrm{X} 1$ = Grandparenting role type; $\mathrm{X} 2$ = Involvement Level; $Z$ = Respect.
} 
participants included in the study. Of these, 300 grandparents completed the study questionnaire, which was delivered to the kindergartens by a personal visit or through the mail between May 23 and June 7, 2011. However, data from 45 grandparents had to be excluded because too many questions were omitted or answered arbitrarily, leaving a sample of 255 participants whose data were considered in the study.

\section{Variables, Measurement, and Operationalization}

The main independent variables were grandparenting role type and involvement level, and the dependent variable was psychological well-being. The study also assessed care burden (stress) as a mediating variable and respect accorded to grandparents as a moderating variable. Involvement was operationalized as the amount of time spent participating in care for their grandchildren, measured based on participants' responses to the survey question How much time do you spend with your grandchildren each day? Psychological well-being was operationalized to include participants' level of depressive symptoms, satisfaction with life, and perceptions of meaning in life. This variable was measured using the Korean form of the Geriatric Depression Scale (KGDS; Chung et al. 1998), the Family Inventory of Life Events and Changes (FILE) measure (McCubbin et al. 1979), and the Satisfaction with Life Scale (SWLS; Diener et al. 1985). Burden was measured using the Grandparent Caregiver Burden Scale (Pruchno 1999), while items from the Familism Scale (Heller 1970) were used to measure respect.

Grandparent role-meaning was analysed according to the typology of Robertson (1977), who identified and defined four categories, as follows:

- Apportioned type: The grandparent recognizes a high level of social normative meaning in their role and engages in close interaction with grandchildren.

- Symbolic type: The grandparent is well aware of the social normative meaning of their role but does not feel a personal attachment to his/her grandchildren and does not intervene from a behavioural aspect.

- Individualized type: The grandparent finds personal meaning, even when the grandparenting role does not carry normative meaning.

- Remote type: The grandparent does not carry out the role of a 'grandparent', even from a behavioural aspect, since this type involves almost never recognizing the social normative meaning of being a grandparent.

To determine participants' role type, a 12-item Likert-scale measure was used that included factor statements for each of two dimensions: personal and social. The personal dimension values personal normative meaning, whereas the social dimension values social normative meaning (see Table 1) (sample factor statements for both dimensions are provided under the Results section). Grandparents who scored high on both the personal and social dimensions were assigned to the apportioned type. Those with low scores on both dimensions represented the remote type. Those who scored high on the personal but low on the social dimension were assigned to the individualized type. Those who scored low on the personal but high on the social dimension were assigned to the symbolic type. Finally, a factor analysis was conducted to ascertain the independence of these two dimensions based on item clustering. 
Table 1 Grandparent Role-meaning (Robertson 1977)

\begin{tabular}{llll}
\hline & & Personal & \\
\cline { 3 - 4 } & & High & Low \\
\hline Social & High & Apportioned & Symbolic \\
& Low & Individualized & Remote \\
\hline
\end{tabular}

\section{Data Analysis}

Chi-square $\left(\chi^{2}\right)$ tests were conducted to examine the distribution of the four grandparenting role types in terms of general participant characteristics. A principal component analysis was used for the factor analysis, with factor loading cut-offs of 0.55 , and a varimax rotation was used. A hierarchical regression analysis was conducted to verify the mediating effect of care burden and to measure the impact of grandparenting role type and involvement level on psychological well-being. The demographic variables (participant characteristics: gender, age, spouse, religion, education, number of children, housemates, material support, health, and living standard) were controlled. Based on Baron and Kenny (1986), mediation effects were assessed using a Sobel test.

\section{Results}

\section{Sample Characteristics}

Table 2 summarizes general demographic characteristics of the sample. Of the 255 participants, $87.8 \%$ were women, and $12.2 \%$ were men. The age group between 61 and 65 years had the highest number of participants $(37.6 \%)$, followed by those aged between 66 and 70 years old (36.5\%) and over the age of $70(16.1 \%)$, respectively. Of the participants, $81.6 \%$ were married. The largest group of participants identified themselves as Catholic (47.1\%), followed by Protestant (25.5\%), Other (14.1\%), and Buddhist (13.3\%). Regarding education, the majority had a high school diploma (48.6\%), followed by those with a university diploma (33.3\%) and those who did not complete high school (18.0\%). Grandparents with four or more grandchildren represented $43.5 \%$ of the sample, while $37.3 \%$ had three and $19.2 \%$ had two grandchildren or fewer. Participants who lived with a spouse accounted for $66.7 \% ; 22.0 \%$ lived with others, and $11.4 \%$ lived alone. In terms of income, the largest group (52\%) lived on 'Property' income (savings, rent, etc.), followed by 'Working' (24.7\%), support from children (9.4\%), their own pensions or severance pay (9\%), and 'Other' (4.7\%). Participants who self-reported as being 'Healthy' accounted for $57.3 \%$ of the sample, versus 'Normal' (38.8\%) and 'Unhealthy' (3.9\%). Finally, with respect to living standard, $60.4 \%$ considered themselves as having a mid-level living standard, while $36.5 \%$ claimed a high-level living standard, and $3.1 \%$ considered themselves as having a low-level standard of living. 
Table 2 Participant characteristics

\begin{tabular}{|c|c|c|c|}
\hline \multicolumn{2}{|l|}{ Category } & \multirow{2}{*}{$\begin{array}{l}\text { Frequency } \\
\text { (Number of participants) } \\
31\end{array}$} & \multirow{2}{*}{$\begin{array}{l}\begin{array}{l}\text { Percent of } \\
\text { sample }(\%)\end{array} \\
12.2\end{array}$} \\
\hline Gender & Male & & \\
\hline & Female & 224 & 87.8 \\
\hline \multirow[t]{4}{*}{ Age } & Less than 60 years & 25 & 9.8 \\
\hline & Between 61 and 65 years & 96 & 37.6 \\
\hline & Between 66 and 70 years & 93 & 36.5 \\
\hline & More than 70 years & 41 & 16.1 \\
\hline \multirow[t]{2}{*}{ Spouse } & Yes & 208 & 81.6 \\
\hline & No & 47 & 18.4 \\
\hline \multirow[t]{4}{*}{ Religion } & Buddhist & 34 & 13.3 \\
\hline & Protestant & 65 & 25.5 \\
\hline & Catholic & 120 & 47.1 \\
\hline & Other & 36 & 14.1 \\
\hline \multirow[t]{3}{*}{ Education } & Less than high school education & 46 & 18.0 \\
\hline & High school education & 124 & 48.6 \\
\hline & University education & 85 & 33.3 \\
\hline \multirow[t]{3}{*}{ Number of children } & 2 or fewer & 49 & 19.2 \\
\hline & 3 & 95 & 37.3 \\
\hline & 4 or more & 111 & 43.5 \\
\hline \multirow[t]{3}{*}{ Housemates } & Live alone & 29 & 11.4 \\
\hline & Live with a spouse & 170 & 66.7 \\
\hline & Live with others & 56 & 22.0 \\
\hline \multirow[t]{5}{*}{ Material support } & Working & 63 & 24.7 \\
\hline & Property income (savings, rent etc.) & 133 & 52.2 \\
\hline & Pension or severance pay & 23 & 9.0 \\
\hline & Supported by children & 24 & 9.4 \\
\hline & Other & 12 & 4.7 \\
\hline \multirow[t]{3}{*}{ Health } & Healthy & 146 & 57.3 \\
\hline & Normal & 99 & 38.8 \\
\hline & Unhealthy & 10 & 3.9 \\
\hline \multirow[t]{3}{*}{ Living standard } & High & 93 & 36.5 \\
\hline & Middle & 154 & 60.4 \\
\hline & Low & 8 & 3.1 \\
\hline Total & & 255 & 100.0 \\
\hline
\end{tabular}

As a baseline for comparison, according to the 2011 census (Seoul Statistical Office 2011), $11 \%$ of the population of Seoul, South Korea was over the age of 65 , and $43 \%$ of these individuals lived with a spouse or alone. Approximately $54.2 \%$ reported having more than a high school education, while $52.7 \%$ provided their own material support. Thus, although comparators are not available for all categories, the present sample characteristics appear to match those of the overall South Korean population fairly well. 


\section{Chi-Square Analysis}

The distribution of the four grandparenting role types across the study sample was found to be as follows: apportioned type $(n=125)$, remote type $(n=100)$, symbolic type $(n=23)$, and individualized type $(n=8)$. Chi-square analyses were performed to examine the distribution of these types in terms of the participant demographics. The results are shown in Table 3.

As seen in Table 3, all demographic variables except 'living with a spouse' differed significantly depending on role type. The remote grandparenting type was most common among male participants $(90.3 \%)$, whereas the apportioned type was most frequent for females $(54.5 \%)$. Relatively few participants were identified in the symbolic and individualized types for both genders.

Participants under the age of 60 were predominately remote-type grandparents $(64.0 \%)$, while those between the ages of 61 and 65 were predominately apportioned type $(56.3 \%)$, as were those between the ages of 66 and $70(52.7 \%)$ and aged 71 and above $(48.8 \%)$.

Those who self-identified as Protestant $(63.1 \%)$ and Catholic $(66.7 \%)$ predominately demonstrated an apportioned role; those who self-identified as Buddhist (88.2\%) and Other $(91.7 \%)$ predominately demonstrated remote type. Participants with less than a high school education had higher incidence of remote role $(91.3 \%)$, while those with a high school $(65.3 \%)$ and university education (48.2\%) predominately reported the apportioned type. Participants with two or fewer grandchildren were more typically remote $(79.6 \%)$, while those with three $(57.9 \%)$ and four or more $(58.6 \%)$ were predominately apportioned. Participants who lived alone $(69.0 \%)$ or with a spouse $(60.0 \%)$ were predominately apportioned, while those who lived with others were predominately remote $(89.3 \%)$. In terms of material support, participants who worked $(66.7 \%)$ or had property income $(60 \%)$ were predominately apportioned. Those with pensions or severance pay (75\%), those supported by their children $(91.7 \%)$, and those who answered Other $(75 \%)$ were predominately remote $\left(\chi^{2}=113.385, d f=12\right.$. $p<0.001)$. Participants who self-identified as healthy were predominately apportioned $(57.5 \%)$, while those who self-identified as normal (53.5\%) and unhealthy (100\%) were predominately remote. Finally, with respect to standard of living, participants with a high standard were predominately apportioned (86\%), while those with a medium $(53.2 \%)$ or low $(100 \%)$ standard were predominately remote.

\section{Hierarchical Regression of Mediation and Interaction Effects}

In this study, a hierarchical regression analysis was also conducted to verify the mediating effect of burden of caring on the impact of grandparent role type and involvement level on psychological wellbeing, as indicated by the measures specified above (meaning of life, stress and depressive mood). A Sobel test was also conducted to verify the significance of the mediating effect. According to Baron and Kenny (1986), three conditions must be fulfilled in order to establish a mediating effect. In the first equation, the independent variable should affect the mediator. In the second equation, the independent variable should affect the dependent variable. In the third and final equation, the mediator should affect the dependent variable. The process thus involved four steps, which are summarized below. 


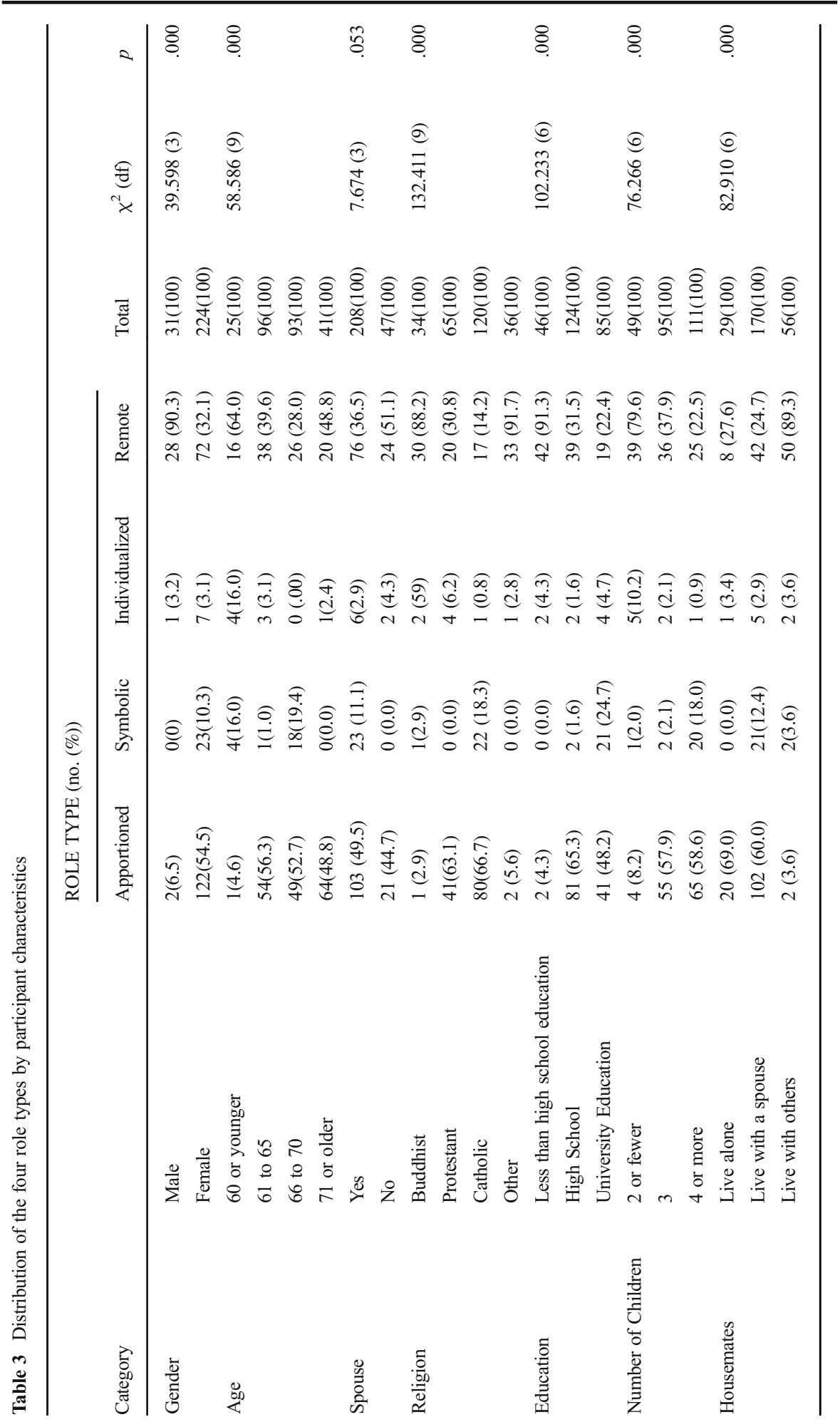




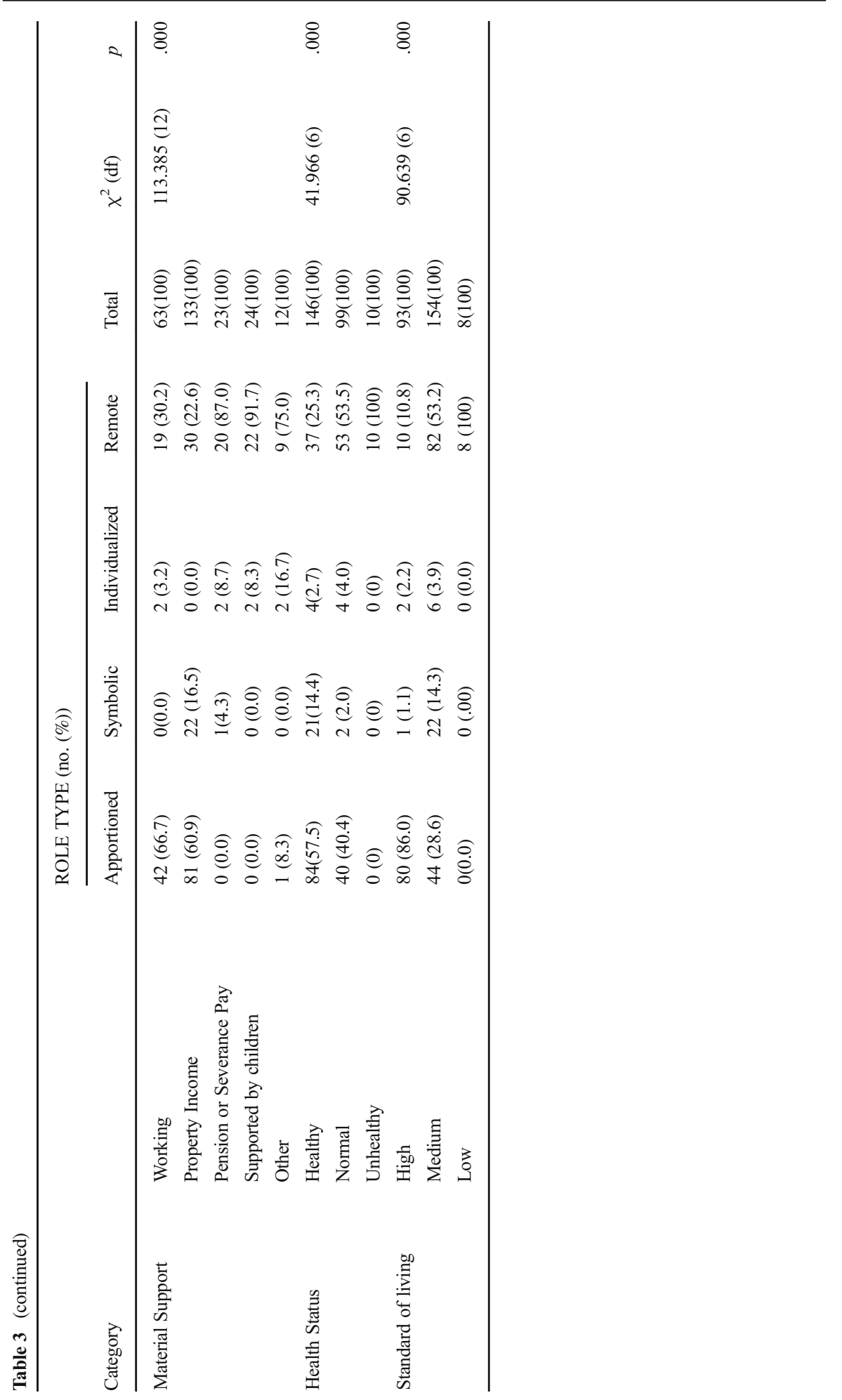


Step 1: Analysis of the effect on burden of caring of the independent variables: grandparenting role type and involvement level. (burden of caring $=\mathrm{B}^{0}+$ $\mathrm{B}^{1} *$ independent variable).

Step 2: Analysis of the effect of the independent variables on psychological wellbeing, measured in terms of meaning of life, stress, and depressive mood. (Psychological Wellbeing $=\mathrm{B}^{0}+\mathrm{B}^{1} *$ independent variables).

Step 3: Analysis of the changes in the coefficient value (B) of each independent variable after controlling for burden of caring. (Psychological wellbeing = $\mathrm{B}^{0}+\mathrm{B}^{1} *$ burden of caring $+\mathrm{B}^{2} *$ independent variables).

Step 4: Sobel test to verify the significance of the mediating effect.

\section{Linearity, Heteroscedasticity, Clustering Correction, Outlier Tests, and Multicollinearity}

In order to the check the regression, linearity, heteroscedasticity, clustering correction, outlier tests and multicollinearity diagnostics were used. Searching for outliers was the first check of the diagnostics, and it was performed using a scatterplot of the histogram and a regression standardized residual. Another element of Multiple Regression Analysis is to find the difference between the observed dependent variable and the forecasted dependent variables, which is the residual. The residual should be distributed normally (normality) when it comes to the forecasted dependent variable's score. At the same time, the residual should assume forecasted dependent variable score and linear correlation (linearity). Also, the residual of the forecasted dependent variable score should be the same for all of the forecasting variables (heteroscadastsicity) (Kennedy 1992). These parameters can be checked using a scatterplot of the forecasted values and residuals to detect extreme values (Kennedy). All of these methods were used in the present study. As a result, data was converted by deviating from normality with respect to the variable depressive mood. In order to convert the data, the log was used in this study. With respect to multicollinearity, it is possible to claim that the correlation among independent variables was excessively high. Thus, for this study, the variance inflation factor (VIF) was checked for verification. All of the VIF values were found to be less than 10 , making it is possible to claim that there was no multi-collinearity. In the case of clustering correction, hypothesis testing was used for logistic regression in Stata Version 10, with standard errors corrected for clustering within kindergartens. Clustering was used rather than estimating random effects for kindergartens because clustering is more statistically conservative.

\section{Mediating Effects}

First, the association between burden of caring and the independent variables, grandparenting role type and involvement level, was analyzed. All categories of participant characteristics, including gender, age, spouse, religion, education, number of children, housemates, material support, health, and living standard, were controlled.

In this study, the remote grandparenting type was used as a reference group, dummy variable, and baseline against which the three other role types - apportioned, symbolic, 
and individualized - were compared. This method is reflected in the results presented in the remainder of this chapter.

As seen in Table 4, when the demographic variables (participant characteristics) gender, age, spouse, religion, education, number of children, housemates, material support, health, and living standard-were controlled, the three other grandparenting role types showed negatively significant compared to the remote type at the significance level of 0.001 . The $\mathrm{R}^{2}$ was $65.2 \%$ and the change of $\mathrm{R}^{2}$ was $19.9 \%$ for the grandparenting role types. Compared to the remote type, the apportioned type showed the least impact of positive burden of caring $(\beta=$ $-0.766, p<0.001)$, followed by the symbolic type $(\beta=-0.385, p<0.001)$ and the individual type $(\beta=-0.148, \mathrm{p}<0.001)$, respectively.

When negative burden of caring was analyzed, the apportioned and symbolic types revealed less impact than the remote type $(\beta=-0.612, p<0.001 \& \beta=-0.271, \mathrm{p}<$ $0.001)$. However, the result for the individualized type was not significant. Thus, it is possible to claim that grandparents of the individualized type did not feel a greater negative sense of burden of caring than did those of the remote type. Finally, the results showed that grandparents of the apportioned type felt a stronger impact of positive feelings such as satisfaction and happiness than of negative feelings such as fatigue and burden.

As can be seen in Table 5, with respect to involvement level, when time spent nurturing grandchildren increased, positive burden of caring decreased $(p<.001)$. However, for negative burden of caring, when nurturing time increased, negative burden of caring increased $(\beta=0.210, p<0.001)$. This means that when nurturing time increased, positive feelings such as happiness and satisfaction decreased, but negative feelings such as fatigue and constraint increased.

Table 6 shows the mediating effect of each of the three non-baseline grandparenting role types on each of the three measures of psychological wellbeing. As can be seen, when the demographic variables (participants characteristics)—gender, age, spouse, religion, education, number of children, housemates, material support, health and living standard - were controlled, all three of the non-baseline grandparenting role types were found to have positively significant effects on meaning of life compared to the remote type. As with the results regarding positive burden of caring, the apportioned type showed the strongest effect $(\beta=0.765, p<0.001)$. With respect to stress, all of the

Table 4 Effect of grandparenting role type on burden of caring

\begin{tabular}{|c|c|c|c|c|c|c|}
\hline & \multicolumn{3}{|c|}{ Positive burden of caring } & \multicolumn{3}{|c|}{ Negative burden of caring } \\
\hline & $\mathrm{B}$ & SE B & $\beta$ & B & SE B & $\beta$ \\
\hline Apportioned type & -1.088 & .094 & $-.766 * * *$ & -1.206 & .137 & $-.612 * * *$ \\
\hline Symbolic type & -.956 & .133 & $-.385 * * *$ & -.960 & .192 & $-.279 * * *$ \\
\hline Individualized type & -.604 & .167 & $-.148 * * *$ & -.414 & .242 & -.073 \\
\hline $\mathrm{R}^{2}$ & \multicolumn{3}{|l|}{.652} & \multicolumn{3}{|l|}{.619} \\
\hline F-value & \multicolumn{3}{|c|}{$34.743 * * *$} & \multicolumn{3}{|c|}{$30.169 * * *$} \\
\hline$\Delta \mathrm{R}^{2}$ & \multicolumn{3}{|c|}{.199} & \multicolumn{3}{|c|}{.123} \\
\hline
\end{tabular}

$* p<.05, * * \mathrm{p}<.01, * * * \mathrm{p}<.001$ 
Table 5 Effect of involvement level on burden of caring

\begin{tabular}{|c|c|c|c|c|c|c|}
\hline & \multicolumn{3}{|c|}{ Positive burden of caring } & \multicolumn{3}{|c|}{ Negative burden of caring } \\
\hline & $\mathrm{B}$ & SE B & $\beta$ & $\mathrm{B}$ & SE B & $\beta$ \\
\hline Involvement level & -.033 & .008 & $-.195^{* * *}$ & .049 & .011 & $.210 * * *$ \\
\hline $\mathrm{R}^{2}$ & \multicolumn{3}{|l|}{.486} & \multicolumn{3}{|l|}{.534} \\
\hline \multirow[t]{2}{*}{ F-value } & \multicolumn{3}{|c|}{$20.884 * * *$} & \multicolumn{3}{|c|}{$25.345 * * *$} \\
\hline & \multicolumn{3}{|l|}{.033} & \multicolumn{3}{|l|}{.038} \\
\hline
\end{tabular}

$* \mathrm{p}<.05, * * p<.01, * * * p<.001$

grandparenting role types were strongly negatively significant, with $\mathrm{F}$ value at $26.231 \%$ and the change of $\mathrm{R}^{2}$ was $13.4 \%$. Compared to the remote type, the apportioned type showed the strongest positive effect $(\beta=0.631, p<0.001)$, followed by the symbolic type $(\beta=0.331, \mathrm{p}<0.001)$, whereas the individualized type showed a negative effect $(\beta=-0.090, p<0.005)$. In the case of depressive mood, the apportioned type had a positively significant relationship, meaning that it may have contributed to increased depressive mood when compared to the remote type. However, the symbolic and individualized types showed negatively significant relationships with depressive mood, which may translate into a positive impact (benefit) on this measure of psychological wellbeing as compared to the apportioned and remote role types.

Table 7 shows the mediating effect of involvement level on each of the three measures of psychological wellbeing. Increased involvement appeared to show a significant positive correlation with meaning of life $(P<.001)$. In terms of stress, when nurturing time increased, stress appeared to decrease, i.e., a negative correlation, which was found to be statistically significant. Thus, it is possible to claim that when the grandparents spent more time nurturing their grandchildren, they tended to experience more satisfaction, happiness and meaning in their lives than those who did not participate in nurturing their grandchildren. However, for depressive mood, when nurturing time increased, no change was observed.

As seen in Table 8, after positive burden of caring was controlled, the apportioned, symbolic and individualized grandparenting role types were all found to be statistically

Table 6 Mediating effect of grandparenting role type on measures of psychological wellbeing

\begin{tabular}{|c|c|c|c|c|c|c|c|c|c|}
\hline & \multicolumn{3}{|c|}{ Meaning of life } & \multicolumn{3}{|l|}{ Stress } & \multicolumn{3}{|c|}{ Depressive mood } \\
\hline & $\mathrm{B}$ & SE B & $\beta$ & $\mathrm{B}$ & SE B & $\beta$ & $\mathrm{B}$ & SE B & $\beta$ \\
\hline Apportioned type & 1.494 & .083 & $.765 * * *$ & -.973 & .112 & $.631 * * *$ & .113 & .026 & $.389 * * *$ \\
\hline Symbolic type & 1.314 & .117 & $.385^{* * *}$ & -.891 & .157 & $.331 * * *$ & .116 & .037 & $-.230 * *$ \\
\hline Individualized type & .822 & .147 & $.147 * * *$ & -.397 & .197 & $-.090 *$ & .135 & .046 & $-.163 * *$ \\
\hline $\mathrm{R}^{2}$ & \multicolumn{3}{|l|}{.856} & \multicolumn{3}{|c|}{.586} & \multicolumn{3}{|c|}{.353} \\
\hline F-value & \multicolumn{3}{|c|}{$110.405^{* * *}$} & \multicolumn{3}{|c|}{$26.231 * * *$} & \multicolumn{3}{|c|}{$10.093 * * *$} \\
\hline$\Delta \mathrm{R}^{2}$ & \multicolumn{3}{|c|}{.198} & \multicolumn{3}{|c|}{.134} & \multicolumn{3}{|c|}{.163} \\
\hline
\end{tabular}

$* p<.05, * * p<.01, * * * p<.001$ 
Table 7 Mediating effect of involvement level on measures of psychological wellbeing

\begin{tabular}{|c|c|c|c|c|c|c|c|c|c|}
\hline & \multicolumn{3}{|c|}{ Meaning of life } & \multicolumn{3}{|l|}{ Stress } & \multicolumn{3}{|c|}{ Depressive mood } \\
\hline & $\mathrm{B}$ & SE B & $\beta$ & $\mathrm{B}$ & SE B & $\beta$ & $\mathrm{B}$ & SE B & $\beta$ \\
\hline Involvement level & .004 & .009 & .018 & -.024 & .009 & $-.134 * *$ & .003 & .002 & -.101 \\
\hline $\mathrm{R}^{2}$ & \multicolumn{3}{|l|}{.658} & \multicolumn{3}{|l|}{.467} & \multicolumn{3}{|l|}{.172} \\
\hline F-value & \multicolumn{3}{|c|}{$42.562 * * *$} & \multicolumn{3}{|c|}{$19.390 * * *$} & \multicolumn{3}{|c|}{$4.575^{* * * *}$} \\
\hline$\Delta \mathrm{R}^{2}$ & \multicolumn{3}{|c|}{.000} & \multicolumn{3}{|c|}{.015} & \multicolumn{3}{|c|}{.009} \\
\hline
\end{tabular}

$* p<.05, * * p<.01, * * * p<.001$

significant $(P<.001)$ in terms of their mediating effects on the dependent variable meaning of life. For the apportioned type, the value of the coefficient $(\beta)$ decreased from 0.765 to 0.677 . Thus, it is possible to claim that there was a partial mediating effect. In case of the symbolic role type, the value of the coefficient decreased from 0.385 to 0.341 . In case of the individualized type, the value of the coefficient decreased from 0.147 to 0.130 . These changes were statistically significant, and therefore it is possible to claim that there was a partial mediating effect for all three grandparenting role types compared to the remote type.

With respect to stress, the change in the coefficient value $(\beta)$ was statistically significant for the apportioned and symbolic types. In the case of the apportioned type, the value decreased from 0.631 to -0.314 , while for the symbolic type it decreased from 0.331 to -0.171 . Meanwhile, for the individualized type the value decreased from -0.090 to -0.028 , showing a partial mediating effect for stress with respect to positive burden of caring for this role type.

With respect to depressive mood, unlike meaning of life or stress, the coefficient value $(\beta)$ increased for one of the role types, namely the apportioned type, for which the change from 0.389 to 0.514 showed no mediating effect. However, the coefficient value decreased from -0.230 to -0.167 for the symbolic type and from -0.163 to

Table 8 Mediating effect of grandparenting role type on measures of psychological wellbeing after controlling for positive burden of caring (PBC)

\begin{tabular}{|c|c|c|c|c|c|c|c|c|c|}
\hline & \multicolumn{3}{|c|}{ Meaning of life } & \multicolumn{3}{|l|}{ Stress } & \multicolumn{3}{|c|}{ Depressive mood } \\
\hline & $\mathrm{B}$ & SE B & $\beta$ & B & SEB & $\beta$ & $\mathrm{B}$ & SEB & $\beta$ \\
\hline PBC & -.157 & .056 & $-.114 * *$ & .450 & .071 & $.414 * * *$ & .033 & .018 & .164 \\
\hline Apportioned type & 1.323 & .102 & $.677 * * *$ & -.484 & .129 & $-.314 * * *$ & .149 & .033 & $.514 * * *$ \\
\hline Symbolic type & 1.163 & .127 & $.341 * * *$ & -.461 & .160 & $-.171 * *$ & -.084 & .040 & $-.167^{*}$ \\
\hline Individualized type & .727 & .149 & $.130 * * *$ & -.126 & .188 & -.028 & -.115 & .047 & $-.138^{*}$ \\
\hline $\mathrm{R}^{2}$ & \multicolumn{3}{|l|}{.861} & \multicolumn{3}{|l|}{.646} & \multicolumn{3}{|l|}{.362} \\
\hline F-value & \multicolumn{3}{|c|}{$105.992 * * *$} & \multicolumn{3}{|c|}{$31.241 * * *$} & \multicolumn{3}{|c|}{$9.721 * * *$} \\
\hline$\Delta \mathrm{R}^{2}$ & \multicolumn{3}{|c|}{.005} & \multicolumn{3}{|c|}{.060} & \multicolumn{3}{|c|}{.009} \\
\hline
\end{tabular}

$* \mathrm{p}<.05, * * p<.01, * * * p<.001$ 
-0.138 for the individualized type. Thus, it showed mediating effects in both of these latter cases.

As seen in Table 9, the findings supported the hypothesis of negative burden of caring as a mediator for the apportioned, symbolic and individualized grandparenting role types. All mediating findings were statistically significant $(P<0.05)$ for meaning of life. The coefficient value $(\beta)$ decreased from 0.765 to 0.712 for the apportioned type, from 0.385 to 0.362 for the symbolic type and from 0.147 to 0.140 for the individualized type. These results may show a partial mediation that is significant at the level of $p<0.001$.

With respect to stress, after negative burden of caring was controlled, the change in the coefficient value $(\beta)$ for each of the role types was as follows: apportioned type decreased from 0.631 to -0.491 , symbolic type decreased from 0.331 to -0.267 and individualized type decreased from -0.090 to -0073 . In this regard, the apportioned and symbolic types showed significant positive correlations, but the individualized type showed a very significant correlation. Thus, the impact of each of the role types showed a mediating effect of negative burden of caring.

With respect to depressive mood, after negative burden of caring was controlled, the coefficient value $(\beta)$ for apportioned type increased from 0.389 to 0.425 , showing no mediating effect. However, the value for the symbolic type decreased from -0.230 to -0.214 and the value for the individualized type decreased from -0.163 to -0.158 . Therefore, it is possible to claim that there was a partial mediating effect for both the symbolic and the individualized types.

As can be seen in Table 10, after positive burden of caring was controlled, involvement level correlated positively with meaning of life, and the coefficient value $(\beta),-0.071$, was significant at the level $P<0.05$. However, the coefficient value increased from 0.018 , so the results showed a suppression effect rather than the hypothesized mediating effect.

With respect to stress, after positive burden of caring was controlled, the coefficient value $(\beta)$ for involvement level decreased from -0.134 to -0.026 . In this regard, it is possible to claim that positive burden of caring had a mediating effect. When positive burden of caring increased, stress also increased; however, when

Table 9 Mediating effect of negative burden of caring (NBC) for grandparenting role type on measures of psychological wellbeing

\begin{tabular}{|c|c|c|c|c|c|c|c|c|c|}
\hline & \multicolumn{3}{|c|}{ Meaning of life } & \multicolumn{3}{|l|}{ Stress } & \multicolumn{3}{|c|}{ Depressive mood } \\
\hline & B & SE B & $\beta$ & B & SE B & $\beta$ & B & SE B & $\beta$ \\
\hline $\mathrm{NBC}$ & -.085 & .039 & $-.085^{*}$ & .180 & .051 & $.229 * *$ & .009 & .012 & .059 \\
\hline Apportioned type & 1.392 & .095 & $.712 * * *$ & -.757 & .126 & $-.491 * * *$ & .123 & .030 & $.425^{* * * *}$ \\
\hline Symbolic type & 1.233 & .122 & $.362 * * *$ & -.718 & .161 & $-.267 * * *$ & -.108 & .039 & $-.214^{* *}$ \\
\hline Individualized type & .787 & .147 & $.140 * * *$ & -.323 & .194 & -.073 & -.131 & .047 & $-.158 * *$ \\
\hline $\mathrm{R}^{2}$ & \multicolumn{3}{|l|}{.859} & \multicolumn{3}{|l|}{.606} & \multicolumn{3}{|l|}{.354} \\
\hline F-value & \multicolumn{3}{|c|}{$104.433 * * *$} & \multicolumn{3}{|c|}{$26.362 * * *$} & \multicolumn{3}{|c|}{$9.387 * * *$} \\
\hline$\Delta \mathrm{R}^{2}$ & \multicolumn{3}{|c|}{.003} & \multicolumn{3}{|c|}{.020} & \multicolumn{3}{|l|}{.001} \\
\hline
\end{tabular}

$* p<.05, * * p<.01, * * * p<.001$ 
Table 10 Impact of involvement level on psychological wellbeing after controlling for positive burden of caring $(\mathrm{PBC})$

\begin{tabular}{|c|c|c|c|c|c|c|c|c|c|}
\hline & \multicolumn{3}{|c|}{ Meaning of life } & \multicolumn{3}{|l|}{ Stress } & \multicolumn{3}{|c|}{ Depressive mood } \\
\hline & B & SE B & $\beta$ & B & SE B & $\beta$ & B & SE B & $\beta$ \\
\hline $\mathrm{PBC}$ & -.630 & .060 & $-.458 * * *$ & .600 & .008 & $.553 * * *$ & -.011 & .017 & -.055 \\
\hline Involvement level & -.016 & .008 & $-.071^{*}$ & -.005 & .008 & -.026 & -.004 & .002 & -.112 \\
\hline $\mathrm{R}^{2}$ & \multicolumn{3}{|l|}{.766} & \multicolumn{3}{|l|}{.625} & \multicolumn{3}{|c|}{.173} \\
\hline F-value & \multicolumn{3}{|c|}{$66.030 * * *$} & \multicolumn{3}{|c|}{$33.562 * * *$} & \multicolumn{3}{|c|}{$4.223 * * *$} \\
\hline$\Delta \mathrm{R}^{2}$ & \multicolumn{3}{|c|}{.108} & \multicolumn{3}{|l|}{.157} & \multicolumn{3}{|c|}{.001} \\
\hline
\end{tabular}

$* \mathrm{p}<.05, * * \mathrm{p}<.01, * * * \mathrm{p}<.001$

involvement level increased, stress decreased slightly, indicating a mediating effect of positive burden of caring.

For depressive mood, the change in the coefficient value $(\beta)$ was not significant even after positive burden of caring was controlled. Nonetheless, since the coefficient value increased slightly, from -.101 to -.112 , it is possible to claim that there was no mediating effect.

Table 11 shows the results of the examination of the mediating effect of negative burden of caring on the impact of involvement level on the three variables of psychological wellbeing. For meaning of life, the coefficient value $(\beta)$ increased from 0.018 to 0.104 . Thus, it is possible to claim that there was no mediating effect with regard to this variable. With respect to stress, the coefficient value increased from -0.134 to -0.241 , so it was also possible to claim that there was no mediating effect. For depressive mood, the coefficient value decreased slightly, from -0.101 to -0.087 . However, even before negative burden of caring was controlled, the change was not significant. Thus, it is not possible to claim that there was no mediating effect.

Table 12 shows the results of the Sobel test that was conducted to verify the mediating effect of positive and negative burden of caring on the impact of involvement level on each of the three measures of psychological wellbeing. It also summarizes the findings regarding the mediating effects of positive and negative burden of caring on

Table 11 Impact of involvement level on psychological wellbeing after controlling for negative burden of caring $(\mathrm{NBC})$

\begin{tabular}{|c|c|c|c|c|c|c|c|c|c|}
\hline & \multicolumn{3}{|c|}{ Meaning of life } & \multicolumn{3}{|l|}{ Stress } & \multicolumn{3}{|c|}{ Depressive mood } \\
\hline & $\mathrm{B}$ & SE B & $\beta$ & B & SE B & $\beta$ & $\mathrm{B}$ & SE B & $\beta$ \\
\hline $\mathrm{NBC}$ & -.406 & .048 & $-.409 * * *$ & .402 & .047 & $.513 * * *$ & -.009 & .013 & -.064 \\
\hline Involvement level & .024 & .009 & $.104 * *$ & -.044 & .008 & $-.241 * * *$ & -.003 & .002 & -.087 \\
\hline $\mathrm{R}^{2}$ & \multicolumn{3}{|l|}{.736} & \multicolumn{6}{|l|}{.570} \\
\hline F-value & \multicolumn{3}{|c|}{$56.279 * * *$} & \multicolumn{6}{|c|}{$29.045^{* * *}$} \\
\hline$\Delta \mathrm{R}^{2}$ & \multicolumn{3}{|c|}{.078} & \multicolumn{6}{|c|}{.123} \\
\hline
\end{tabular}

$* p<.05, * * p<.01, * * * p<.001$ 
Table 12 Results of sobel test

\begin{tabular}{llll}
\hline & Meaning of life & Stress & Depressive mood \\
\hline Positive burden of caring & & & \\
Apportioned type & $2.725^{* *}$ & $-5.559 * * *$ & -1.879 \\
Symbolic type & $2.612^{* *}$ & $-4.754 * * *$ & -1.841 \\
Individualized type & $2.22^{*}$ & $-3.141 * *$ & -1.685 \\
Involvement level & $3.839^{* * *}$ & $-4.119 * * *$ & 0.825 \\
Negative burden of caring & & & -.357 \\
Apportioned type & $2.116^{*}$ & $-3.276 * *$ & -.356 \\
Symbolic type & $1.998^{*}$ & $-2.883 * *$ & -.350 \\
Individualized type & 1.346 & -1.539 & -1.159 \\
Involvement level & $-3.941^{* * *}$ & $3.951 * * *$ & \\
\hline
\end{tabular}

$* \mathrm{p}<.05, * * \mathrm{p}<.01, * * * \mathrm{p}<.001$

the impact of role type and involvement level on the variables associated with psychological wellbeing in the present study.

All in all, as shown in Table 13, both positive and negative burden of caring had partial mediating effects on the impact of role type on meaning of life and stress for all three role types, except that there was no mediating effect for negative burden on the impact of individualized role type on stress, while depressive mood showed no mediating effects. In addition, with respect to involvement level, the only positive finding was a full mediating effect of positive burden of caring on the impact on stress.

\section{Interaction effects}

To examine the interaction effect of the feeling of respect, a hierarchical regression was used. Only significant and meaningful interactions are reported here.

As seen in Table 14, when grandparents felt respected, stress decreased. Stress increased with positive burden of caring, but the interaction was not statistically significant $(\beta=0.051$, significance level $p<0.5)$.

As seen in Table 15, the interaction between feeling of respect and negative burden of caring showed a significant negative correlation for meaning of life

Table 13 Summary of mediating effects of positive and negative burden of caring (PBC and NBC) on the impact of role type and involvement level on psychological wellbeing

\begin{tabular}{|c|c|c|c|c|c|c|}
\hline & \multicolumn{2}{|c|}{ Meaning of life } & \multicolumn{2}{|l|}{ Stress } & \multicolumn{2}{|c|}{ Depressive mood } \\
\hline & $\mathrm{PBC}$ & NBC & PBC & NBC & $\mathrm{PBC}$ & NBC \\
\hline Apportioned type & Partial & Partial & Partial & Partial & - & - \\
\hline Symbolic type & Partial & Partial & Partial & Partial & - & - \\
\hline Individualized type & Partial & Partial & Partial & - & - & - \\
\hline Involvement level & - & - & Full & - & - & - \\
\hline
\end{tabular}


Table 14 Interaction effect between feeling of respect and positive burden of caring (PBC) for stress

\begin{tabular}{|c|c|c|c|c|c|c|c|c|c|}
\hline & \multicolumn{3}{|l|}{ Stress } & \multicolumn{3}{|l|}{ Stress } & \multicolumn{3}{|l|}{ Stress } \\
\hline & $\mathrm{B}$ & SE B & $\beta$ & B & SE B & $\beta$ & $\mathrm{B}$ & SE B & $\beta$ \\
\hline Apportioned type & -.522 & .143 & $-.338 * * *$ & -.294 & .144 & $-.191 *$ & -.248 & .158 & -.161 \\
\hline Symbolic type & -.373 & .185 & $-.139 *$ & -.221 & .180 & -.082 & -.165 & .196 & -.061 \\
\hline Individualized type & -.229 & .192 & -.052 & -.071 & .186 & -.016 & -.053 & .188 & -.012 \\
\hline Respect & -.340 & .071 & $-.393 * * *$ & -.206 & .073 & $-.239 * *$ & -.208 & .073 & $-.241 * *$ \\
\hline $\mathrm{PBC}$ & & & & .372 & .075 & $.343 * * *$ & .433 & .114 & $.399 * * *$ \\
\hline $\mathrm{R} * \mathrm{PBC}$ & & & & & & & .068 & .095 & .051 \\
\hline $\mathrm{R}^{2}$ & \multicolumn{3}{|l|}{.622} & \multicolumn{3}{|l|}{.657} & \multicolumn{3}{|c|}{.658} \\
\hline F-value & \multicolumn{3}{|c|}{$28.180 * * *$} & \multicolumn{3}{|c|}{$30.535 * * *$} & \multicolumn{3}{|c|}{$28.600 * * *$} \\
\hline$\Delta \mathrm{R}^{2}$ & \multicolumn{3}{|c|}{.036} & \multicolumn{3}{|c|}{.035} & \multicolumn{3}{|c|}{.001} \\
\hline
\end{tabular}

$* \mathrm{p}<.05, * * \mathrm{p}<.01, * * * \mathrm{p}<.001$

( $\beta=-0.065, p<0.05)$. With respect to stress and depressive mood (not shown), the interaction effects were not statistically significant (stress: $\beta=-0.019, p<$ 0.05; depressive mood: $\beta=-0.043, \mathrm{p}<0.05)$. However, compared to the results for the interaction effect between respect and positive burden of caring, these results support the view that participants in the three non-baseline role types who felt respected tended to experience more positive burden of caring in the form of feelings of satisfaction than negative burden of caring in the form of stress and depressive mood.

With respect to the impact of involvement level on psychological wellbeing (Table 16), feeling of respect showed an interaction effect on the mediating

Table 15 Interaction effect between feeling of respect and negative burden of caring (NBC) for meaning of life

\begin{tabular}{|c|c|c|c|c|c|c|c|c|c|}
\hline & \multicolumn{3}{|c|}{ Meaning of life } & \multicolumn{3}{|c|}{ Meaning of life } & \multicolumn{3}{|c|}{ Meaning of life } \\
\hline & B & SE B & $\beta$ & B & SE B & $\beta$ & B & SE B & $\beta$ \\
\hline Apportioned type & 1.005 & .101 & $.515 * * *$ & .977 & .105 & $.500 * * *$ & .904 & .111 & $.462 * * *$ \\
\hline Symbolic type & .754 & .131 & $.212 * * *$ & .736 & .132 & $.216^{* * * *}$ & .636 & .140 & $.187 * * *$ \\
\hline Individualized type & .640 & .136 & $.114 * * *$ & .630 & .136 & $.113 * * *$ & .670 & .137 & $.120 * * *$ \\
\hline Respect & .368 & .050 & $.336 * * *$ & .358 & .051 & $.327 * * *$ & .366 & .051 & $.334 * * *$ \\
\hline NBC & & & & -.034 & .036 & -.034 & -.094 & .047 & $-.095^{*}$ \\
\hline $\mathrm{R} * \mathrm{NBC}$ & & & & & & & -.093 & .045 & $-.065^{*}$ \\
\hline $\mathrm{R}^{2}$ & \multicolumn{3}{|l|}{.882} & \multicolumn{3}{|l|}{.883} & \multicolumn{3}{|l|}{.885} \\
\hline F-value & \multicolumn{3}{|c|}{$128.587 * * *$} & \multicolumn{3}{|c|}{$120.006^{* * *}$} & \multicolumn{3}{|c|}{$114.248 * * *$} \\
\hline$\Delta \mathrm{R}^{2}$ & \multicolumn{3}{|l|}{.026} & \multicolumn{3}{|c|}{.000} & \multicolumn{3}{|l|}{.002} \\
\hline
\end{tabular}

$* \mathrm{p}<.05, * * \mathrm{p}<.01, * * * \mathrm{p}<.001$ 
Table 16 Interaction effect of feeling of respect on the mediating effect of negative burden of caring (NBC) on the effect of involvement level on meaning of life

\begin{tabular}{|c|c|c|c|c|c|c|c|c|c|}
\hline & \multicolumn{3}{|c|}{ Meaning of life } & \multicolumn{3}{|c|}{ Meaning of life } & \multicolumn{3}{|c|}{ Meaning of life } \\
\hline & B & SE B & $\beta$ & B & SE B & $\beta$ & $\mathrm{B}$ & SE B & $\beta$ \\
\hline Involvement level & -.009 & .007 & -.040 & -.001 & .007 & -.006 & -.003 & .007 & -.015 \\
\hline Respect & .696 & .044 & $.635 * * *$ & .618 & .051 & $.564 * * *$ & .594 & .050 & $.542^{* * * *}$ \\
\hline NBC & & & & -.132 & .044 & $-.133^{* *}$ & -.224 & .051 & $-.226^{* * *}$ \\
\hline $\mathrm{R} * \mathrm{NBC}$ & & & & & & & -.167 & .048 & $-.117^{* *}$ \\
\hline $\mathrm{R}^{2}$ & .831 & .837 & .845 & & & & & & \\
\hline F-Value & \multicolumn{3}{|c|}{$98.925 * * *$} & \multicolumn{3}{|c|}{$95.020 * * *$} & \multicolumn{3}{|c|}{$93.173 * * *$} \\
\hline$\Delta \mathrm{R}^{2}$ & \multicolumn{3}{|c|}{.172} & \multicolumn{3}{|c|}{.006} & \multicolumn{3}{|c|}{.008} \\
\hline
\end{tabular}

$* \mathrm{p}<.05, * * p<.01, * * * p<.001$

effect of negative burden of caring only with regard to meaning of life $(\beta=$ -0.117 at $P<0.01)$.

\section{Discussion and Practice Implications}

The study sought to examine how role type (and perceptions of role type), involvement level, burden of care, and respect impacted grandparents' psychological well-being (see Fig. 1). Overall, in terms of the study's first two hypotheses, the analyses demonstrated that grandparent role type significantly predicted psychological well-being. Specifically, participants in the non-baseline role types (i.e., those who participated in grandparenting) tended to experience a high sense of life meaning and reported relatively low stress and depressive symptoms. Thus, participation in grandparenting was related to increased levels of positive affect (such as happiness, satisfaction, and joy) and low levels of negative affect (such as stress, frustration, depression, and fatigue). With respect to level of involvement, stress tended to decrease $(\beta=-0.134)$ when involvement was high, but no relationship emerged with feelings of meaning or depressive mood.

Moreover, grandparenting role type significantly predicted burden of care, in which both a positive and negative sense of burden was low for all three non-baseline role types compared to the remote type. In other words, participation in grandparenting was related to a mixture of both positive and negative affect. With respect to involvement level, the amount of time participants devoted to grandparenting was related to a decrease in positive affect and increased negative affect.

In addition, as predicted in hypothesis 3 , burden of care mediated the relationship between role type and involvement level on psychological well-being. When both positive and negative care burden were included as mediators, reported life meaning increased, as well as above-baseline stress levels; however, there was no association with depressive mood. Involvement level had a mediating effect for positive care burden predicting increased stress. 
Finally, as predicted in hypothesis 4, respect moderated the mediating effect of care burden on role type and involvement level in predicting psychological well-being. Specifically, when grandparents across the other three role types felt respected by their adult children, they reported a greater sense of life meaning and exhibited less stress and depressive symptoms when compared to the baseline remote type grandparents or those grandparents who did not feel respected.

\section{Implications for Practice}

At least four major implications for social work policy and practice can be drawn from these results. First, since it appears that grandparents' participation in nurturing their grandchildren can influence their psychological well-being, social work policy makers should strive to provide resources and support for seniors in order for those who might benefit to engage more readily with these important roles. In South Korea, where the study was conducted, this could be an important area for raising public and institutional awareness in light of the statistical increase in suicides among economically challenged elderly individuals noted at the beginning of this paper (Seoul Statistical Office 2005).

Second, given that significant moderated mediation emerged in terms of care burden and grandparent roles and involvement, social work practitioners should be aware of the important interactions among grandparents, adult children, and grandchildren when providing family counselling and other resources. Furthermore, efforts should be made to promote and achieve synergy across generations within the family unit. Such approaches can have benefits for all family members, including helping grandparents feel an increased sense of pride, rather than a sense of isolation, while providing young parents with models for positive family value systems. Intergenerational interactions could also help younger individuals with regard to negative perceptions they might harbour toward ageing, enabling them to develop a more realistic attitude toward the ageing process.

Third, as compared to social exchange theory (Marbach 1995) or some other exchange model, the present study suggests that there are advantages to applying dynamic practice models such as Bowen's (1971) family system therapy to social work practice. Such an approach is especially appropriate in a South Korean context, where most families encompass more than two generations. According to Bowen, individuals are best understood through an assessment of the entire family system and each individual's role. The goal of family system therapy is to help family members improve communication, solve family problems, understand and handle special family situations, and create a more functioning home environment. In this approach, problems are treated by changing the way the system works rather than by trying to 'fix' a specific member. Thus, family system therapy is used to help both families and individual family members of all ages cope with and overcome various challenges, including quests toward emotional fulfilment within new roles across the age spectrum.

Finally, the results have implications regarding the impact of grandparent attitudes and behaviour patterns within the changing social dynamics of the twenty-first century. Family patterns in South Korea are changing, with significant demographic shifts that include rapid growth in multi-generational families, later marriages, fewer children, and increased family breakdown and re-formations. Furthermore, these shifts are occurring over a much longer lifetime than was once the norm. Moreover, while the relative number of children is decreasing, with both the elderly population and percentage of 
working mothers increasing in South Korea, many grandparents are taking on new, active caregiving roles. Thus, it is vital that social work practitioners be prepared to assist elderly clients and their families in order to address these evolving roles and the impacts they have on the family unit.

\section{Limitations and Research Implications}

Several limitations of the present study should be noted. First, the sample consisted of only 255 grandparents recruited from 14 kindergartens in Seoul. Although some of the sample characteristics appeared to match the broader South Korean population, the sample size and geographic distribution were too limited for generalizability.

Second, the ages of both the grandparents (participants) and their grandchildren were truncated. Grandparents who participated were mostly in the 61-65 age range, while their respective grandchildren were all between 3 and 5 years old. Thus, the study sample was also limited in scope regarding representation of the possible grandparentgrandchild age spectrum.

Third, women vastly outnumbered men in the current sample (224 grandmothers and only 31 grandfathers). Thus, future research should attempt to oversample from grandfathers in order to provide more valid gender comparisons.

Fourth, some participants did not complete all of the questionnaire measures (or, in some cases, individual items within these measures) thoroughly or thoughtfully. An attempt was made to prevent this shortcoming by providing participants with certain necessities in connection with their participation; however, this did not fully eliminate the need to exclude some of the data.

Finally, as the study used a cross-sectional design, the results cannot contribute substantially to the understanding of how the parameters considered here might change over time. Thus, future studies should address progress in participants' grandparenting experiences, including possible changes in the impact of moderating and mediating factors.

\section{Conclusion}

The present study contributed to the understanding of factors impacting grandparents' psychological well-being when fulfilling their grandparenting roles. Overall, the results suggest that although Grandparenting can be stressful, it can also be a positive experience that adds new vitality to the lives of elderly adults. As a society, it is important that we provide grandparents with understanding, support, and respect as they carry out their roles. To contribute to this effort, further research in this area should be encouraged, and legislators, policy makers, and practitioners should endeavour to implement research-based recommendations in ways that promote elder adult health and well-being.

\section{Compliance with Ethical Standards}

Conflict of Interest The author declares that she has no conflict of interest. 
Informed Consent Informed consent was obtained from all individual participants included in the study.

Ethical Treatment of Experimental Subjects (Animal and Human) All procedures performed in studies involving human participants were executed in accordance with the ethical standards of the institutional and/or national research committee and with the 1964 Helsinki declaration and its later amendments or comparable ethical standards.

Open Access This article is distributed under the terms of the Creative Commons Attribution 4.0 International License (http://creativecommons.org/licenses/by/4.0/), which permits unrestricted use, distribution, and reproduction in any medium, provided you give appropriate credit to the original author(s) and the source, provide a link to the Creative Commons license, and indicate if changes were made.

\section{References}

Alliance of Kindergartens in Seoul, South Korea (2010). Retrieved from Alliance of Kindergartens in Seoul, South Korea Reports. www.seoul.nka.kr. Accessed 2 June 2007.

Baron, R. M., \& Kenny, D. A. (1986). The moderator-mediator variable distinction in social psychological research: conceptual, strategic, and statistical considerations. Journal of Personality and Social Psychology, 51, 1173-1182.

Bowen, M. (1971). Family therapy and family group therapy. In H. Kaplan \& B. Sadok (Eds.), Comprehensive group psychotherapy (pp. 394-421). Baltimore: Williams and Wilkins.

Burton, L. M. (1992). Black grandparents rearing children of drug-addicted parents: stressors, outcomes, and social service needs. Gerontologist, 32(6), 744-751.

Chen, X., \& Silverstein, M. (2000). Intergenerational social support and the psychological well-being of older parents in China. Research on Aging, 22, 43-65.

Cherlin, A. J., \& Furstenberg, F. F. (1986). The new American grandparent. New York: Basic Books.

Chung, I. K., Kwak, D. I., Cho, S. H., \& Lee, H. S. (1998). A preliminary study on standardization of Korean form of geriatric depression scale (KGDS). The Korean Neuropsychiatric Association, 37(2), 340-351.

Cox, C. (2000). Empowerment practice: Implications for interventions with African American and Latina custodial grandparents. Mental Health and Aging, 6(4), 385-397.

Diener, E., Emmons, R. A., Larsen, R. J., \& Griffin, S. (1985). The satisfaction with life scale. Journal of Personality Assessment, 49, 71-75.

Fan, R. (2006). Confucian filial piety and long term care for aged parents. HealthCare Ethics Committee Forum, 18(1), 1-17.

Gonzalez, J., \& Anuncibay, R. (2008). Intergenerational grandparent/grandchild relations: the socioeducational role of grandparents. Educational Gerontology, 34(1), 67-88.

Goodman, C., \& Silverstein, M. (2002). Grandmothers raising grandchildren: family structure and well-being in culturally diverse families. The Gerontologist, 42(5), 676-689.

Heller, P. L. (1970). Familism scale: a measure of family solidarity. Journal of Marriage and Family, 32, 7380.

Jendrek, M. P. (1994). Grandparents who parent their grandchildren: circumstances and decisions. The Gerontologist, 34, 206-216.

Kelley, S. J., Whitley, D., Sipe, T. A., \& Yorker, B. C. (2000). Psychological distress in grandmother kinship care providers: the role of resources, social support, and physical health. Child Abuse and Neglect, 24(3), 311-321.

Kennedy, P. (1992). A guide to econometrics. Oxford: Blackwell Publishers Ltd.

Kennedy, J. F., \& Keeney, V. T. (1988). The extended family revisited: grandparents rearing grandchildren. Child Psychiatry and Human Development, 19, 26-35.

Kim, D. (2006). Psychological well-being of custodial grandmothers and related factors (Unpublished master's thesis). Seoul National University Graduate School of Social Work, South Korea.

Kornhaber, A., \& Forsyth, S. (1994). Grandparent power: how to strengthen the vital connection among grandparents, parents, and children. New York: Crown.

Kwon, I. S. (2000). The relationship between burden and social support for grandmothers caring for their grandchildren. Journal of Child Nursing, 6(2), 212-223. 
Lee, S. H. (2005). A study of burden and reward for grandparents raising grandchildren (Unpublished master's thesis). Shinla University, South Korea.

Marbach, J. H. (1995). Social exchange within triads of family generations. Paper presented at the conference of the International Social Network, London, UK.

McCubbin, H. I., Wilson, L., \& Patterson, J. M. (1979). Family inventory of live events and changes. St. Paul: Family Stress Project, University of Minnesota.

Minkler, M., Fuller-Thomson, E., Miller, D., \& Driver, D. (1997). Depression in grandparents raising grandchildren. Archives of Family Medicine, 6, 445-452.

Neugarten, B. L. (1976). Adaptation and the life cycle. The Counseling Psychologist, 6, 16-20.

Neugarten, B. L., Havighurst, R. J., \& Tobin, S. S. (1968). Personality and patterns of aging. In B. L. Neugarten (Ed.), Middle age and aging: a reader (pp. 173-177). Chicago: University of Chicago Press.

Ohk, G. H. (2005). Grandparents raising grandchildren. Journal of Korean Home Management, 23(3), 103114.

Park, E. H. (2012). Grandparenting for grandparents' sake: a study of the relationship between psychological wellbeing and level of involvement in grandparenting (Unpublished doctoral dissertation). Yonsei University, South Korea.

Pruchno, R. (1999). Raising grandchildren: the experiences of black and white grandmothers. The Gerontologist, 39, 209-221.

Robertson, J. F. (1977). Grandmotherhood: a study of role conceptions. Journal of Marriage and the Family, $26,165-174$.

Rodgers-Farmer, A. Y. (1999). Parenting stress, depression, and parenting in grandmothers raising their grandchildren. Children and Youth Services Review, 21(5), 377-388.

Seoul Statistical Office (2005). Aging statistics.

Seoul Statistical Office (2011). Aging statistics.

Strawbridge, W. J., Walhagen, M. I., Shema, S. J., \& Kaplan, G. A. (1997). New burdens or more of the same? Comparing grandparent, spouse, and adult-child caregivers. The Gerontologist, 37(4), 505-510.

Strom, R. D., Lee, T. J., Strom, P. S., Nakagawa, K., \& Beckert, T. E. (2008). Taiwanese grandmothers: strengths and learning needs as perceived by grandmothers, mothers, and granddaughters. Educational Gerontology, 34(9), 812-830.

Szinovacz, M., DeViney, S., \& Atkinson, M. P. (1999). Effects of surrogate parenting on grandparents' wellbeing. Journal of Gerontology, 54B(6), S376-S388.

Eon-Ha Park holds the degrees of Bachelor of Science (Child and Family Studies, Syracuse University, Syracuse, New York, 2003), Master of Science in Social Work (New York University, New York, New York, 2006) and PhD in Social Welfare (Yonsei University, Seoul, South Korea, 2012). Since 2006, Dr. Park has been an Associate Professor in the Department of Social Welfare and Early Child Education at Daedong College in Busan, South Korea, where she has also served as Director of International Affairs since 2012. Her research interests include Human Development and Social Environment, Child and Family Welfare, Social Work Practice, and Social Work Field Instruction. 